\title{
Editorial
}

\section{Advances in Remote Sensing of Flooding}

\section{Yong Wang}

Department of Geography, Planning, and Environment, East Carolina University, Greenville, NC 27858, USA; E-Mail: wangy@ecu.edu; Tel.: +1-252-328-1043; Fax: +1-252-328-6054

Academic Editor: Miklas Scholz

Received: 10 October 2015 / Accepted: 6 November 2015 / Published: 12 November 2015

\begin{abstract}
With the publication of eight original research articles, four types of advances in the remote sensing of floods are achieved. The uncertainty of modeled outputs using precipitation datasets derived from in situ observations and remote sensors is further understood. With the terrestrial laser scanner and airborne light detection and ranging (LiDAR) coupled with high resolution optical and radar imagery, researchers improve accuracy levels in estimating the surface water height, extent, and flow of floods. The unmanned aircraft system (UAS) can be the game changer in the acquisition and application of remote sensing data. The UAS may fly everywhere and every time when a flood event occurs. With the development of urban structure maps, the flood risk and possible damage is well assessed. The flood mitigation plans and response activities become effective and efficient using geographic information system (GIS)-based urban flood vulnerability and risk maps.
\end{abstract}

Keywords: flood; flood risk analyses and mitigation; geographic information system (GIS); mapping flood extent and assessing flood damage; remote sensing and geospatial technologies and datasets

\section{Introduction}

Once water in a stream or river overflows its banks, the water submerges nearby dry uplands. A flood event occurs. The awesome power of the floodwater threatens human lives, damages infrastructure and buildings, and may trigger mudslides [1,2]. For example, the Yangtze River flood in China in 1931 was the most deadly flood event in the 20th century. The death toll reached $\sim 3.7$ million [3]. Today, floods still kill about 100 people and cause damages exceeding $\$ 70$ billion annually in the 
US [1]. Thus, floods can devastate socioeconomic activities of humans at local, regional, and even national levels.

After the landfall of Hurricane Sandy near New Jersey and New York in the US in October of 2012, and a low pressure system stalled near South Carolina (SC) and North Carolina (NC) in the US in October of 2015, flooding and flood damage have been documented by ground pictures, aerial photos, and satellite images. The remotely sensed data have saturated televisions, computer screens, and social media. As observed in 2012, the mayor of New York City retracted his order in relation to Sandy from a "not a big deal" event to an extremely dangerous one in less than $24 \mathrm{~h}$. His ultimate order to evacuate saved thousands of lives. Although SC citizens were warned that the flood was a 1000-year flood event, the death toll along SC roadways rose regardless. Therefore, it is important to quickly predict and to determine the extent of flooding and the land use type under the floodwater in a flood event.

As humans are facing ever-changing environments and also advancing in science and technology, especially with remote sensing, we as scientists are obligated to predict and to capture the extent of flooding in an efficient and effective manner. This type of information is essential to decision-makers and emergency responders, as well as concerned citizens. Accessing, publicizing, and sharing such critical information can greatly assist comprehensive preparation, emergency response, and relief activity. Therefore, the objective of the Special Issue "Advances in Remote Sensing of Flooding" is to present advances in the analysis and mapping of flood risk and flood events using predominantly remote sensing techniques and datasets. Eight original research papers were published after a rigorous peer-review process. Their contributions are highlighted next.

\section{Thought, Knowledge, and Contribution}

\subsection{Uncertainty in Precipitation Products Remotely Sensed by Ground and Satellite Sensors}

Water moves among the hydrosphere, atmosphere, and lithosphere of the Earth. When studying the hydrological cycle, one tends to start from precipitation. Precipitation can be in the forms of drizzle, rain, freezing rain, snow, sleet, and hail. Precipitation data are collected directly using rain gauges, and indirectly using ground- or satellite- based remote sensors. A rain gauge offers accurate measurements at a point for drizzle and rainfall. However, two issues exist with the gauge measurement. The density of the gauge stations is low worldwide. The gauge is ineffective or even not suitable to measure freezing rain, snow, sleet, or hail. Remote sensors can resolve the spatial coverage issue and measure the precipitation in all six forms. However, without the calibration using in situ data, there is the uncertainty of the remotely sensed precipitation data. The uncertainty can lead to not only erroneous results in scientific research, but also to mistakes in decision-making processes when emergency personnel is conducting rescue missions during the course of a devastating flood event. Thus, research related to the uncertainty of precipitation data is important.

Chintalapudi et al. [4] investigated the sensitivity of a distributed hydrological model using precipitation datasets from rain gauges, NEXRAD (Next-Generation Radar) Multi-sensor Precipitation Estimator (MPE), Precipitation Estimation from Remotely Sensed Information (PERSIANN) $0.25^{\circ}$, PERSIANN CCS: 3 h, PERSIANN CCS: 1 h, Tropical Rain Measuring Mission (TRMM) 3B42V7, and Climate Prediction Center (CPC) MORPHing Technique (CMORPH). The hydrologic response of 
the Guadalupe River basin covering an area of $1232 \mathrm{~km}^{2}$ in Texas was studied and cross-examined with storm events in 2007. They compared the direct and indirect measurements of the precipitation, and found significant biases in the satellite rainfall products and large variations in the estimated amounts. Caution should be exercised in the interpretation and application of simulated results that vary greatly using different datasets. After the calibration of TRMM 3B42V data using the rain gauge data, the simulated stream flows matched the observed ones of two storm events. Therefore, remotely sensed rainfall products coupled with rain gauge data were viable. More importantly, the estimation of the flood flow within a river basin was satisfactory.

\subsection{Better Remotely Sensed and Geospatial Datasets for Flood Risk Analysis, Mitigation, and Response Activity}

Great attention is paid to assessing the extent of a flood using remotely sensed optical, radar, digital elevation model (DEM), and river gauge data. The popularity of algorithms that use these datasets increases due to efficiency and effectiveness, availability, and low cost [5]. As more and more satellites are launched into space to collect data globally, and countries one after another implement the open and free data policy, the concern of data availability decreases greatly. Additionally, the US National Research Council (NRC) in 2007 stated that the nation's elevation data were inadequate to support the Federal Emergency Management Agency (FEMA, US)'s floodplain mapping. New collection of national elevation data was needed. LiDAR should be the primary technological means [6]. In response, the United States Geological Survey (USGS) has led the effort to create the nationwide LiDAR dataset since 2008 [7]. With the LiDAR data, a better national elevation dataset could be produced. Initiated in 2012, the three-dimensional (3D) elevation program further responded to the growing need for high quality topographic data and for a broad range of other $3 \mathrm{D}$ depictions of the natural and man-made features in the US [8]. That being said, articles in which researchers explore the new technologies and datasets are summarized.

Jalonen et al. [9] used the terrestrial laser scanner technology and its data to determine the characteristics of vegetated areas. Thus, an improved accuracy level in the modeling of floodplain flow was achieved. Turner et al. [10] developed procedures to combine the ground-based terrestrial laser scanner and airborne LiDAR data properly. As compared to a flood event and with the combined datasets, they increased the accuracy levels in flood extent, volume, and maximum flood height than those if the airborne LiDAR data were used alone. Owing to the penetration ability of microwave energy through vegetation canopy, the flood extent especially under the canopy was assessed [11]. The decomposition of polarimetric synthetic aperture radar (SAR) data greatly affected the robustness and reliability of the change detection method in wetland mapping. Taking advantage of the HEC-RAS (Hydrologic Engineering Center-River Analysis System, US Army Corps of Engineering, [12]) model development, and of the advances in data acquisition and GIS, Jung et al. [13] reduced the uncertainty in the estimation of the flood discharge. Therefore, the exploration of the technological means and combined use of multiple remotely sensed datasets improved the mapping results of flood events, and advanced our understanding of the flood vulnerability in local communities. 


\subsection{Unmanned Aircraft System (UAS)}

An unmanned aircraft system (UAS) is an aircraft that is operated without direct human intervention from within or on the aircraft. The UAS consists of elements required for the pilot in command to operate safely and efficiently in the airspace system of a nation. The elements include communication links and components that control the aircraft. As the technology continues to improve and the cost to operate drops rapidly, the UAS is performing a variety of tasks with greater operational flexibility and at a lower cost than comparable manned aircraft. Under the current FAA (Federal Aviation Administration, US) rules, a person can operate the UAS five miles $(8 \mathrm{~km})$ away from an airport and with an altitude not exceeding $400 \mathrm{ft}$. $(120 \mathrm{~m})$ without permission. Further relaxation of the rule is anticipated to expand the operational airspace. Thus, when a flood or disaster event occurs, a team of personnel equipped with an UAS can be assembled and deployed on the spot immediately. After the establishment of a launch site, the team conducts flight operations and provides high resolution data to emergency responders on the site and to a command post or center where it is further analyzed to assist in rescue efforts. Due to rapid deployment, the temporal constraint affecting the application of satellite observation in flood mapping (e.g., [14,15]) does not exist. Of a low flight altitude, the UAS typically flies under clouds if they exist. Optical sensors onboard the UAS are not affected by cloud cover. Therefore, the UAS attracts attention in data collection and application from a wide spectrum of users, and plays a transformative role in urban infrastructure management, farming, public safety, national security and defense, military missions, and disaster response.

Using high resolution optical data acquired by an UAS, Feng et al. [16] studied the potential for fast and accurate detection of inundated areas under complex urban landscapes in Yuyao, China. The inundation was caused by waterlogging. Texture features and spectral signatures were derived from the high resolution data in the separation of different ground objects and delineation of flooded/non-flooded areas. The overall accuracy for the flood mapping was $87.3 \%$, and the Kappa coefficient 0.746 . Their results demonstrate that the UAS is an ideal platform for remote sensing data acquisition and application in urban flood assessment. The developed method is able to extract the inundated and non-inundated areas satisfactorily, which in turn results in additional applications of remote sensing technology to aid emergency responders and decision-makers.

\subsection{Risk Analysis and Information Dissemination}

In flood risk analyses, mitigation plans, and response activities during the course of a flood event, one is constantly concerned about the socioeconomic damage and loss potentially caused by the flood. Although remotely sensed data have been used to assess the damage from local to regional extents (e.g., [2,14,15,17-19]), estimates of possible structure damage and monetary loss, which are two key components in the flood risk analysis, are still a challenge. Using high resolution optical satellite data and airborne LiDAR data, Gerl et al. [20] derived a land cover classification and map of urban structure types, and then input them into their multi-parameter flood damage models including regression tree models. The damage models were for the pre-hazard modeling and estimation of flood losses in flood risk mitigation, management, mapping, and financial appraisals. They evaluated the models against the 2002 Elbe flood in Germany. The modeled flood losses were in the same order of 
magnitude as the official damage data. In addition, single-family houses suffered significantly higher damage than other urban structure types. Therefore, better delineation of the houses using very fine resolution remote sensing data that may be collected by UAS flights before, during, and after a flood event should improve the damage modeling results substantially such that the accuracy level of the flood risk assessment could further increase.

Ouma and Tateishi [21] offered their expertise for preparing public-based flood mapping and estimating flood risks in growing urban areas in the Eldoret Municipality, Kenya. An integration of the Analytical Hierarchy Process (AHP) and GIS analysis was used to model the magnitude of flood risk areas with rainfall, elevation and slope, drainage network and density, land use and land cover types, and soil type considered. An urban flood risk index was developed to quantify the degree of vulnerability and exposure to the flood danger such that researchers, personnel in governmental agencies at different levels and in private sectors, and the general public could be well informed.

With the post-flood recovery efforts in the New Jersey and New York areas after Hurricane Sandy in 2012, and the South Carolina flood in 2015, as well as other flood events around the globe, a new level of awareness and understanding of the vulnerability in local communities and businesses is reached. Actions taken to reduce or eliminate long-term flood risk to people and their properties as laid out in the flood mitigation plans are increasingly recognized as the basis for the long-term resilience and sustainability of communities and as integral features of community planning and decision-making. Therefore, if we want to make significant progress towards reducing flood vulnerability, a pivotal belief and unifying theme is that not just governmental agencies but citizens and communities need to be effectively engaged and informed in mitigation planning. They need to be empowered to adopt and implement appropriate measures. Consequently, lives are saved and properties/assets spared.

\section{Conclusions}

Since the first acquisition of aerial photography from a hot air balloon in 1858 over Paris, France, humans have made great progress in the acquisition of remotely sensed data using platforms of aircraft, satellites, space shuttles, model aircraft, and unmanned aircraft systems. With the analysis of remote sensing data, humans obtain information to parameterize flood models, delineate flood extent, and estimate flood damage. We now can not only be reactive during the course of a flood event, but also proactive through flood risk analysis and mitigation. Flood hazard, exposure, and vulnerability modeling at local and regional levels, as well as at a national level, can be supported by remote sensing. Therefore, the fundamental objective of the Special Issue is to solicit studies that document advances in flood risk analyses and mapping as well as event modeling using primarily remote sensing techniques and datasets.

The objective has been met with the publication of eight original research articles. The articles or studies furthered the understanding of the uncertainty of modeled outputs using the precipitation datasets derived from in situ observations and remote sensors. With the development and availability of terrestrial laser scanners and airborne LiDAR coupled with high resolution optical and radar imagery, researchers characterized vegetated areas, depicted topography, and detected the absence or presence of water under vegetation canopy so that accuracy levels in the estimation of flood flow, extent, and surface floodwater height were improved. The use of an UAS was seen as the game 
changer in the acquisition and application of remotely sensed data. The UAS can fly everywhere and every time when a flood event occurs. Based on remote sensing datasets, multi-parameter damage models and regression tree models were capable of estimating the potential flood risk and damage for a modeled flood scenario in advance of an event. Humans were well informed with GIS-based urban flood vulnerability and risk maps. Our flood mitigation plans and response activities would become effective and efficient as well.

Nevertheless, two fundamental factors existed yesterday, exist today, and will exist tomorrow. Areas such as floodplains and coastal plains that are flood-prone are unfortunately experiencing rapid population growth and social and economic development. The flood hazards will unavoidably continue. Therefore, our society, socioeconomic activities, and daily life will be impacted by a flood event one way or another. Humans will continue to experience costly damage caused by floods as well as other nature- and human- induced disasters. Advances and knowledge in remote sensing for flood studies should be one of the assets to minimize vulnerability, to foster sustainable growth, and eventually, to achieve balanced risk reduction and socioeconomic development.

\section{Acknowledgments}

Yong Wang, the Guest Editor, greatly appreciates the research community for contributing a wide range of original research manuscripts, and the publisher, MDPI, for allocating resources making this Special Issue possible.

\section{Conflicts of Interest}

The author declares no conflict of interest.

\section{References}

1. National Oceanic and Atmospheric Administration (NOAA)/National Weather Service (NWS). Floods: The Awesome Power; NOAA/PA 200467; NOAANWS: Silver Spring, MD, USA, 2010; p. 16.

2. Klemas, V. Remote Sensing of Floods and Flood-Prone Areas: An Overview. J. Coast. Res. 2015, 31, 1005-1013.

3. National Oceanic and Atmospheric Administration (NOAA). NOAA's Top Global Weather, Water and Climate Events of the 20th Century. Available Online: http://www.noaanews.noaa.gov/ stories/s334b.htm (accessed on 6 October 2015).

4. Chintalapudi, S.; Sharif, H.O.; Xie, H. Sensitivity of Distributed Hydrologic Simulations to Ground and Satellite Based Rainfall Products. Water 2014, 6, 1221-1245.

5. Wang, Y. Mapping Extent of Floods: What We Have Learned and How We Can Do Better. Natl. Hazards Rev. 2002, 3, 68-73.

6. National Research Council (NRC). Elevation Data for Floodplain Mapping; The National Academies Press: Washington, DC, USA, 2007; p. 68.

7. Stoker, J.; Harding, D.; Parrish, J. The Need for a National Lidar Dataset. Photogr. Eng. Remote Sens. 2008, 9, 1066-1068. 
8. Sugarbaker, L.J.; Constance, E.W.; Heidemann, H.K.; Jason, A.L.; Lukas, V.; Saghy, D.L.; Stoker, J.M. The 3D Elevation Program Initiative-A Call for Action; U.S. Geological Survey Circular 1399: Reston, VA, USA, 2014; p. 35.

9. Jalonen, J.; Järvelä, J.; Virtanen, J.P.; Vaaja, M.; Kurkela, M.; Hyyppä, H. Determining Characteristic Vegetation Areas by Terrestrial Laser Scanning for Floodplain Flow Modeling. Water 2015, 7, 420-437.

10. Turner, A.B.; Colby, J.D.; Csontos, R.M.; Batten, M. Flood Modeling Using a Synthesis of Multi-Platform LiDAR Data. Water 2013, 5, 1533-1560.

11. Schmitt, A.; Brisc, B. Wetland Monitoring Using the Curvelet-Based Change Detection Method on Polarimetric SAR Imagery. Water 2013, 5, 1036-1051.

12. Hydrologic Engineering Center, US Army Corps of Engineers. Available online: http://www. hec.usace.army.mil/software/hec-ras/ (accessed on 6 October 2015).

13. Jung, Y.; Merwade, V.; Yeo, K.; Shin, Y.; Lee, O.S. An Approach Using a 1D Hydraulic Model, Landsat Imaging and Generalized Likelihood Uncertainty Estimation for an Approximation of Flood Discharge. Water 2013, 5, 1598-1621.

14. Wang, Y.; Colby, J.D.; Mulcahy, K.A. An efficient method for mapping flood extent in a coastal floodplain using Landsat TM and DEM data. Int. J. Remote Sens. 2002, 23, 3681-3696.

15. Wang, Y. Using Landsat 7 TM data acquired days after a flood event to delineate the maximum flood extent on a coastal floodplain. Int. J. Remote Sens. 2004, 25, 959-974.

16. Feng. Q.; Liu, J.; Gong, J. Urban Flood Mapping Based on Unmanned Aerial Vehicle Remote Sensing and Random Forest Classifier-A Case of Yuyao, China. Water 2015, 7, 1437-1455.

17. Gianinetto, M.; Villa, P.; Lechi, G. Post-flood damage evaluation using Landsat TM and ETM+ data integrated with DEM. IEEE Trans. Geosci. Remote Sens. 2006, 44, 236-243.

18. Mallinis, G.; Gitas, I.Z.; Giannakopoulos, V.; Maris, F.; Tsakiri-Strati, M. An object-based approach for flood area delineation in a transboundary area using ENVISAT ASAR and LANDSAT TM data. Int. J. Digit. Earth 2011, 6, S124-S136.

19. Ogashawara, I.; Curtarelli, M.P.; Ferreira, C.M. The use of optical remote sensing for mapping flooded areas. Int. J. Eng. Res. Appl. 2013, 3, 1-5.

20. Gerl, T.; Bochow, M.; Kreibich, H. Flood Damage Modeling on the Basis of Urban Structure Mapping Using High-Resolution Remote Sensing Data. Water 2014, 6, 2367-2393.

21. Ouma, Y.O.; Tateishi, R. Urban Flood Vulnerability and Risk Mapping Using Integrated Multi-Parametric AHP and GIS: Methodological Overview and Case Study Assessment. Water 2014, 6, 1515-1545.

(C) 2015 by the authors; licensee MDPI, Basel, Switzerland. This article is an open access article distributed under the terms and conditions of the Creative Commons Attribution license (http://creativecommons.org/licenses/by/4.0/). 